\title{
New Target Genes for the Peroxisome Proliferator-Activated Receptor- $\gamma$ (PPAR $\gamma$ ) Antitumour Activity: Perspectives from the Insulin Receptor
}

\author{
Daniela P. Foti, ${ }^{1,2}$ Francesco Paonessa, ${ }^{1}$ Eusebio Chiefari, ${ }^{1}$ and Antonio Brunetti ${ }^{1,3}$ \\ ${ }^{1}$ Department of Clinical and Experimental Medicine "G. Salvatore", University of Catanzaro "Magna Græcia”, \\ V.le Europa (Loc. Germaneto), 88100 Catanzaro, Italy \\ ${ }^{2}$ Chair of Clinical Pathology, University of Catanzaro "Magna Græcia", V.le Europa (Loc. Germaneto), 88100 Catanzaro, Italy \\ ${ }^{3}$ Chair of Endocrinology, University of Catanzaro "Magna Græcia", V.le Europa (Loc. Germaneto), 88100 Catanzaro, Italy
}

Correspondence should be addressed to Antonio Brunetti, brunetti@unicz.it

Received 12 January 2009; Accepted 6 May 2009

Recommended by Jihan Youssef

\begin{abstract}
The insulin receptor (IR) plays a crucial role in mediating the metabolic and proliferative functions triggered by the peptide hormone insulin. There is considerable evidence that abnormalities in both IR expression and function may account for malignant transformation and tumour progression in some human neoplasias, including breast cancer. PPAR $\gamma$ is a ligand-activated, nuclear hormone receptor implicated in many pleiotropic biological functions related to cell survival and proliferation. In the last decade, PPAR $\gamma$ agonists-besides their known action and clinical use as insulin sensitizers - have proved to display a wide range of antineoplastic effects in cells and tissues expressing PPAR $\gamma$, leading to intensive preclinical research in oncology. PPAR $\gamma$ and activators affect tumours by different mechanisms, involving cell proliferation and differentiation, apoptosis, antiinflammatory, and antiangiogenic effects. We recently provided evidence that PPAR $\gamma$ and agonists inhibit IR by non canonical, DNA-independent mechanisms affecting IR gene transcription. We conclude that IR may be considered a new PPAR $\gamma$ "target" gene, supporting a potential use of PPAR $\gamma$ agonists as antiproliferative agents in selected neoplastic tissues that overexpress the IR.
\end{abstract}

Copyright (c) 2009 Daniela P. Foti et al. This is an open access article distributed under the Creative Commons Attribution License, which permits unrestricted use, distribution, and reproduction in any medium, provided the original work is properly cited.

\section{Structure and Biological Function of the IR}

The peptide hormone insulin regulates the metabolism and growth of most cells [1]. In target tissues, it is involved in anabolic processes to produce proteins, polysaccharides, nucleic acids, and lipids. For this complex task, its action implicates three major sites of metabolic regulation. At the plasma membrane, insulin increases the transport of ions, glucose, and other substrates; in the cytoplasm and its organelles, it activates a numer of intracellular enzymes, such as glycogen synthase; in the nucleus, insulin regulates the synthesis of RNA and DNA. The first step in insulin action is its binding to the IR, a phylogenetically ancient receptor tyrosine kinase protein embedded in the plasma membrane of virtually all cells [2-5]. Therefore, the IR plays a critical role in both directing the hormone to a specific target tissue and programming the biological response of the tissue to the hormone. The IR belongs to the tyrosine kinase growth factor receptor family. When insulin binds to the IR, the receptor becomes activated and induces a cascade of intracellular events that will lead to several metabolic and growth promoting effects. The IR consists of two identical extracellular alpha subunits $(130 \mathrm{kDa})$ that house insulin binding domains, and two transmembrane beta subunits $(95 \mathrm{kDa})$ that contain ligand activated tyrosine kinase activity in their intracellular domains [2-5]. A further understanding of the nature of the IR and its relationship to other receptors has been provided by the cloning of the human IR gene [6-8]. Upon binding of insulin to the alpha subunits, the receptor is first activated by tyrosine autophosphorylation, and then the IR tyrosine kinase phosphorylates various intracellular effector molecules (such as IRSs) which in turn alters their activity, thereby generating a biological response [3-5]. In this context, a big effort has been made by scientists to unravel intracellular signaling 
pathways involving metabolic or mitogenic responses $[9,10]$. A bulk of evidences demonstrate that mitogenic stimuli triggered by growth factors are able to regulate different cell-cycle checkpoints [11]. Insulin stimulation activates the IR/IRS/PI3K/PDK1 pathway, leading to the activation of $\mathrm{S} 6 \mathrm{~K}$, which is crucial for ribosome biosynthesis, and necessary for $G_{0}-G_{1}$ transition. S6k is also stimulated by TOR, which induces the translation of cell-cycle regulators, such as cyclin $D$, mediating progression through the $G_{1}$ phase. Cyclin D is also a target for the Ras/ERK cascade induced by insulin, leading to a synergistic effects on cell proliferation [10-12] (Figure 1).

The interaction between IR and other ligands of the IGF (insulin-like growth factor) system [13] implicates an even more complex scenario. The IR exists as two splice variant isoforms: the IR-B isoform that is responsible for signaling metabolic responses involved mainly in the regulation of glucose uptake and metabolism by increasing glucose transporter molecules on the plasma membrane of the insulinresponsive tissues muscle, liver, and fat, and the IR-A isoform, that is expressed in certain tumours (such as mammary cancers), signals predominantly mitogenic responses and is capable of binding IGF-II with high affinity $[14,15]$. As a consequence of these cellular activities, abnormalities of IR expression and/or function can facilitate the development of several metabolic and neoplastic disorders in humans as well as in animal models. In addition, hybrid heterodimeric receptors consisting of insulin and IGF-I receptor subunits may form and could play a role in receptor signaling in normal and abnormal tissues [13].

\section{Molecular and Clinical Significance of the IR in Cancer}

Dysfunctional IR signaling is implicated in certain common dysmetabolic disorders, including obesity, type 2 diabetes, the dysmetabolic syndrome $\mathrm{X}$, and the polycystic ovary syndrome [16-19]. Also, clinical syndromes due to mutations in the IR gene have been identified in patients with genetic forms of severe insulin resistance $[20,21]$ A relation between IR and cancer has been established following the observation that overexpression of functional IRs can occur in human breast cancer and other epithelial tumours including ovarian and colon cancer, in which the IR may exert its oncogenic potential via abnormal stimulation of multiple cellular signaling cascades, enhancing growth factor-dependent proliferation and/or by directly affecting cell metabolism [22-27]. On the other hand, epidemiological and clinical evidence points to a link between insulin resistant syndromes such as obesity and type 2 diabetes and cancer of the colon, liver, pancreas, breast and endometrium. The mechanistic link between insulin resistance and cancer is unknown, but constitutive activation of the tyrosine kinase activity of IR and related downstream signaling pathways by chronic sustained hyperinsulinemia (a hallmark of insulin resistance) in these clinical syndromes appears to have a role in the neoplastic transformation process [2830]. Mechanisms due to hyperinsulinemia that promote malignancy and neoplastic progression include the increase in IGF-I and sex hormones bioavailability, the increase in proinflammatory cytokines, and oxidative stress. Although the molecular mechanisms that cause neoplastic transformation, sustaining tumor progression in the presence of IR hyperexpression and/or hyperstimulation are not fully understood, an explanation for increased IR expression in epithelial tumours has been recently provided by us for several human breast cancers, in which overexpression of the transcription factor AP2- $\alpha$ (activator protein $2-\alpha$ ) accounted for increased IR expression in neoplastic breast tissue [31]. In these cases, it has been demonstrated that transactivation of the IR gene by AP- $2 \alpha$ represented a fundamental prerequisite for AP- $2 \alpha$ to activate IR gene transcription in neoplastic breast tissue. Similarly, a functional link between IR, and cyclin D1 has been recently described in pancreatic cancer [32]. Thus, a better understanding of the mechanisms responsible for increased IR expression may contribute to identify new therapeutic targets for tumours with abnormal IR expression and/or function $[22,33]$.

\section{Regulation of the IR Gene Expression}

In target cells the IR has been shown to be under the regulation of hormones, metabolites, and differentiation [34]. To further understand the regulation of the IR, we and others have identified and analyzed the IR promoter region [6-8]. This region extends over 1,800 bases 5' upstream from the IR gene ATG codon. The IR promoter has no TATA or CAAT boxes, and includes multiple transcription initiation sites, reflecting a feature common to the promoters of many constitutively expressed genes (so-called housekeeping genes). The IR is expressed at low levels in most cells and this expression appears to be driven in part by a series of GGGCGG repeats (in the region -400 to -650 ), which are putative binding sites for the mammalian transcription factor Sp1. The IR is expressed at higher levels in differentiated target tissues such as muscle and fat. At these levels, tissue-specific and ubiquitous nuclear transcription factors cooperate to induce IR gene transcription. We have previoulsy identified two distinct, functionally active DNA sequences, C2 and E3, within the IR gene promoter, which had a significant ability to drive IR gene transcription [8]. The molecular mechanisms regulating IR gene expression are being elucidated and evidence has been provided showing that the architectural transcription factor (High Mobility Group A1 Protein) HMGA1 is required for proper transcription of the IR gene in cells expressing IRs. HMGA1 acts on the IR gene promoter as an element necessary for the formation of a transcriptionally active multiproteinDNA complex involving, in addition to the HMGA1 protein, the ubiquitously expressed transcription factor (specificity protein 1) Sp1, and (CCAAT-enhancer binding protein beta) $\mathrm{C} / \mathrm{EBP} \beta$. By potentiating the recruitment and binding of Sp1 and $\mathrm{C} / \mathrm{EBP} \beta$ to the IR promoter, HMGA1 greatly enhances the transcriptional activities of these factors in the context of the IR gene $[35,36]$. Transcriptional activation of the human IR gene by HMGA1, Sp1, and $\mathrm{C} / \mathrm{EBP} \beta$ requires the assembly and cooperation among these various nuclear 


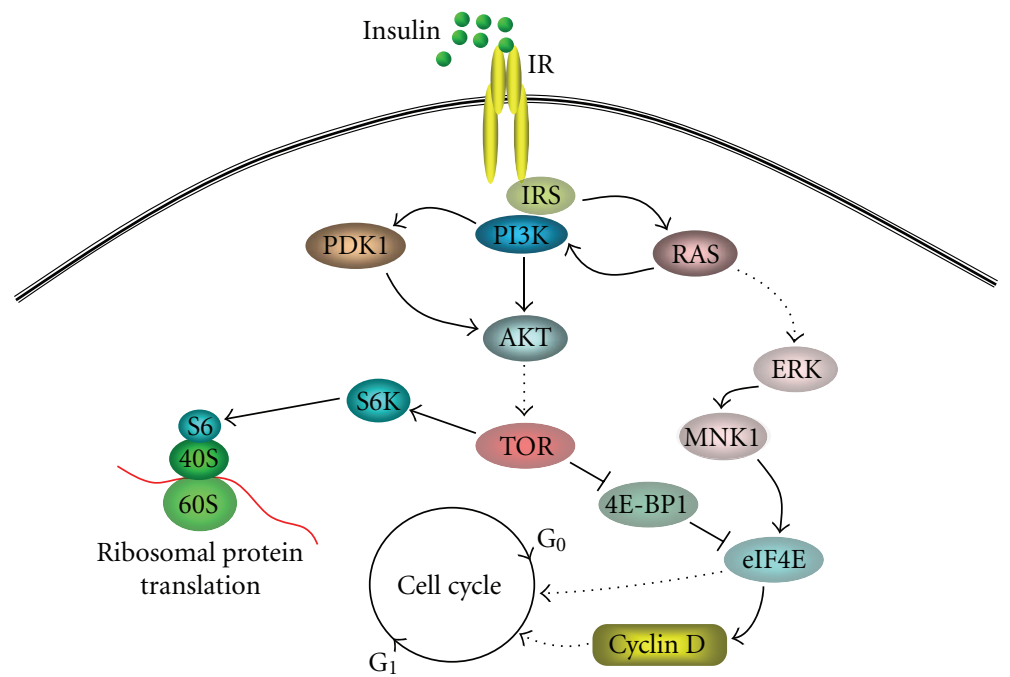

FIGURE 1: Upon binding of insulin, the IR undergoes autophosphorylation which enables the receptor to have a kinase activity and phosphorylates various cytoplasmic substrates, such as IRSs. From this point, signaling proceeds via a variety of signaling pathways (i.e., PI3K signaling pathway, Ras and MAP kinase cascade) that are responsible for the metabolic, growth-promoting and mitogenic effects of insulin.

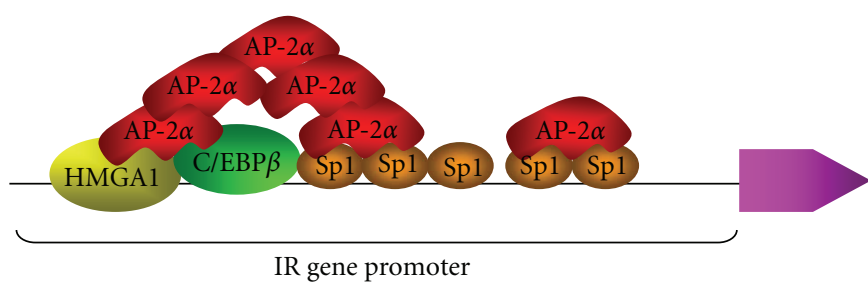

(a)

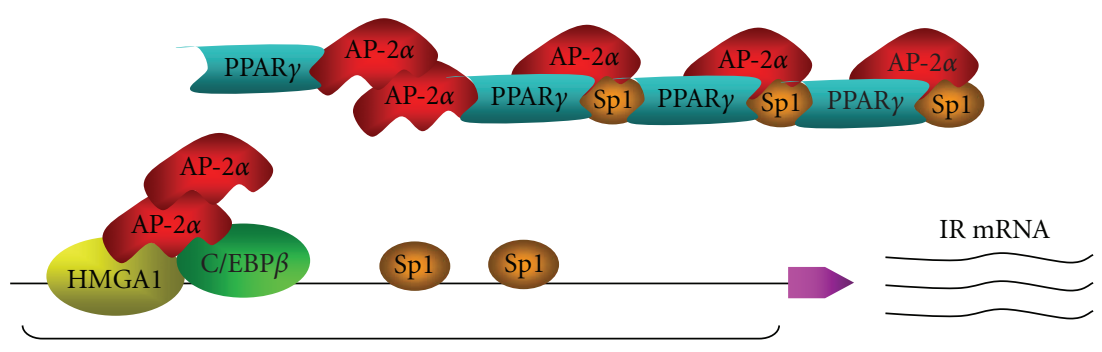

IR gene promoter

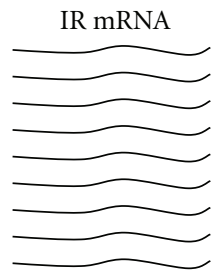


cell types, including liver, skeletal muscle, breast, prostate, colon, lung, monocytes, macrophages, and $\mathrm{B}$ lineage cells [43-46]. Besides a fundamental role in lipid metabolism, PPAR $\gamma$ plays a number of pleiotropic effects, that include a critical role in placental vascularization, myocardial health, and embryonic development $[47,48]$. It also influences the production of cytokines, growth factor release, cell cycle progression, leading to differentiation-inducing, antiinflammatory and anti-proliferative effects [49-51]. PPAR $\gamma$ generally exterts its biological function as heterodimer with the retinoid-X-receptor through binding to a specific cis-acting sequence on DNA-a peroxisome proliferator response element (PPRE) — to initiate transcription [37, 50]. To act as transcription factor, PPAR $\gamma$ requires activation by binding its ligand. The PPAR $\gamma$ activators identified so far include naturally occurring compounds, as some unsaturated fatty acids, some anti-inflammatory moleculessuch as a prostaglandin $\mathrm{J} 2$ metabolite (15-deoxy-D12,14PGJ2)-, oxidized low-density lipoprotein (LDL) particles 9and 13-HODE (hydroxyoctadeca-10E,12Z-dienoic acid) [37, 49], and synthetic compounds, mainly represented by the thiazolidinediones (TZDs) [52], a class of insulin-sensitizing drugs widely used in the treatment of type 2 diabetes mellitus $[52,53]$. Most of the known target genes that are transcriptionally activated by PPAR $\gamma$ belong to the pathway of metabolism and transport of lipids [42, 49]. However, PPAR $y$ may also repress gene transcription. In monocytes and macrophages, for example, it reduces IL-4 (interleukin4) expression. Also, it reduces proinflammatory proteins, like (tumor necrosis factor $\alpha$ ) TNF- $\alpha$, (interleukin-1) IL-1, (inducible nitric oxide synthetase) iNOS, and proinflammatory transcription factors such as (activator protein-1) AP1, (signal transducer and activator of transcription) STAT, and (nuclear factor-kB) NF-kB [54-56]. The mechanisms by which this occurs is unclear. It is generally accepted that in the unliganded state, PPAR $\gamma$ can form weak interactions with (nuclear receptor corepressor) $\mathrm{NcOR}$ and (silencing mediator of retinoid and thyroid hormone receptors) SMRT to repress target gene expression [57]. Target genes that mediate the anticancer activity of the activated PPAR $y$ are still largely undefined and can be related to a wide range of processes including tumour cell differentiation, apoptosis, anti-proliferative effects, and modulation of angiogenic phenotype of the tumour microenvironment.

\section{Effects of PPAR $\gamma$ on the IR Gene}

Studies aimed at understanding whether IR could constitute a target gene for PPAR $\gamma$ have been performed in several cultured cell lines expressing variable amounts of PPAR $\gamma$. In HepG2 human hepatoma cells IRs are relatively abundant, while endogenous PPAR $y$ is barely detectable. Protein expression studies showed that IR protein content was considerably reduced in HepG2 cells overexpressing $\operatorname{PPAR} \gamma(\sim 50 \%$ less than control cells), and this reduction was more pronounced in PPAR $\gamma$-overexpressing cells exposed to TZDs. It has been postulated that PPAR $\gamma$ could affect IR content by blunting IR gene transcription. To this end, reporter gene studies have been performed using the pIR-
CAT recombinant vector that contains the entire 5'-flanking region of the human IR gene [36]. Forced expression of PPAR $\gamma$ in HepG2 cells transfected with pIR-CAT determined a $\sim 50 \%$ reduction in CAT activity that was similar to the reduction observed in cells exposed to rosiglitazone alone, and resulted more marked in PPAR $\gamma$-overexpressing cells simultaneously treated with TZD rosiglitazone. These findings were confirmed in PPAR $y$ overexpressing MCF-7 human breast cancer cells, a cell line naturally expressing only detectable levels of PPAR $y$ [58], and 3T3-L1 adipocytes producing relatively high amounts of endogenous PPAR $\gamma$ [59]. Exposure of both cell lines to either rosiglitazone and/or ciglitazone considerably reduced IR gene transcription [60]. When the recombinant plasmid pCAT-C2 was transfected into HepG2 cells (and the other cell lines), PPAR $\gamma$, and TZDs, either alone or in combination, inhibited pCAT-C2 activity to the same extent than they did in HepG2 cells transfected with the full-length pCAT-IR promoter, indicating that interference of PPAR $\gamma$ and agonists with IR genetranscription machinery occurs at the level of the proximal promoter region, C2. This conclusion was supported by the observation that in experiments using the pCAT-E3 reporter vector, containing the more distant E3 sequence of the IR gene, no effects on CAT activity were observed in cells exposed to PPAR $y$ and/or TZDs. However, no PPRE have been identified on the promoter region of the IR gene. A similar observation has been previously provided by us for the transcription factor AP- $2 \alpha$, for which DNA-binding activity was undetectable within the IR gene promoter, and transactivation of the IR gene by AP- $2 \alpha$ occurred indirectly through physical and functional cooperation with HMGA1 and Sp1 [31]. Therefore, we postulated that PPAR $y$ could perturb IR gene transcription via noncanonical mechanisms interfering with the "enhanceosome" complex formation implicated in transcriptional activation of the IR gene. This hypothesis was confirmed by GST-pull-down studies, followed by electrophoresis mobility shift assay and chromatin immunoprecipitation analyses, demonstrating that PPAR $y$ physically interacted with Sp1, AP- $2 \alpha$ (in selected cell lines) and, to a lesser extent, with $\mathrm{C} / \mathrm{EBP} \beta$ and prevented binding of AP- $2 \alpha$ to Sp 1 protein, as well as of Sp1 and C/EBP $\beta$ to their DNA consensus sites within the IR gene locus [60].

Thus, overexpression and/or activation of PPAR $y$ may adversely affect IR gene transcription in the absence of PPRE on the IR gene promoter. By causing a displacement of Sp1, $\mathrm{AP}-2 \alpha$, and $\mathrm{C} / \mathrm{EBP} \beta, \mathrm{PPAR} \gamma$ may play significant molecular roles in the transcriptional activities of these factors in the context of the IR gene, both in physiology and pathology (Figure 2). These findings are consistent with the notion that IR is regulated by PPAR $\gamma$ through PPRE-independent mechanisms. Further, they are in line with the hypothesized antineoplastic effects of PPAR $\gamma$ and TZD, and support a potential use of PPAR $\gamma$-agonists as antiproliferative agents in selected neoplastic tissues, overexpressing IRs.

\section{Discussion}

The IR is critical in the insulin-mediated effects on cell metabolism and cell growth. Various studies have shown that 
IRs are increased in most human breast cancers, and both ligand-dependent malignant transformation and increased cell growth occur in cultured breast cells overexpressing the IR [31, 61, 62]. Also, overexpression of functional IRs has been involved in thyroid carcinogenesis [63]. In all these cases, the IR can exert its oncogenic potential in malignant cells via abnormal stimulation of multiple cellular signaling cascades, enhancing growth factor-dependent proliferation and/or by directly affecting cell metabolism.

The TZDs are insulin-sensitizing drugs that improve insulin sensitivity in insulin-resistant states such as type 2 diabetes mellitus and obesity. These drugs are high-affinity ligands for the nuclear receptor $\operatorname{PPAR} \gamma$, which regulate transcription of target genes involved in the homeostasis of nutrients. In addition to the effects on lipid and glucose metabolism, many evidences have shown that PPAR $\gamma$ and its ligands play an important role in modulating many processes, including cell proliferation and differentiation. Both breast and thyroid neoplastic cells express $\operatorname{PPAR} \gamma$, and PPAR $y$ agonists have been shown to inhibit proliferation in these and other cell systems [58, 64]. In this light, studies have been performed to assess the effects of PPAR $y$ on IR expression. Results from our group have shown that IR gene transcription and expression were reduced in cells with forced PPAR $y$ expression, or TZD-induced PPAR $y$ activation. Cotreatment with both PPAR $\gamma$ and TZDs further reduced IR protein and mRNA. In this context, treatment with specific PPAR $\gamma$ siRNA or with PPAR $\gamma$ antagonists should be necessary to better understand PPAR $\gamma$-dependent effects of TZDs. If from one hand this seems to exclude the possibility that TZDs may act as insulin sensitizers through the IR, on the other hand this results are compatible with the pleiotropic effects of PPAR $\gamma$. In this regard, the IR may be considered a new "target" gene that accounts for the antimitogenic response to PPAR $y$ and its agonists, and this is the first description of a cell membrane tyrosine kinase receptor involved in PPAR $\gamma$ induced antiproliferative mechanisms.

We showed that PPAR $\gamma$ physically interacted with Sp1, $\mathrm{C} / \mathrm{EBP} \beta$, and $\mathrm{AP}-2 \alpha$ reducing IR gene transcription in the absence of PPAR $\gamma$ DNA-binding sites on the IR gene. We suggested that, in the absence of PPRE in the context of the IR promoter, this nuclear receptor may produce its adverse effects on IR gene expression by interacting physically with these factors, thus reducing their availability to the basic transcription machinery of the IR gene. With a similar mechanism involving Sp1/PPAR $\gamma$ protein interaction, PPAR $\gamma$ has been shown to exert an antiproliferative role by suppressing transcription of the thromboxane receptor, the cyclin-dependent kinase inhibitor p21, and the fibronectin genes [65-67]. The molecular mechanism by which PPAR $y$ inhibits IR gene expression is therefore in agreement with the increasing repertoire of "noncanonical" PPAR $\gamma$ target genes that now encompasses non-PPRE containing genes [50]. Many potential "target" genes of $\operatorname{PPAR} \gamma$, regulated by DNA-independent mechanisms, have been already reported, including bcl-2 (oncogene B-cell leukemia 2, $\beta$-catenin, and the PTEN (phosphatase and tensin homolog) tumor suppressor gene [68-70]. However, how PPAR $y$ and its agonists may induce their antiproliferative effects is not fully understood yet. Recently, non-genomic cross-talks between PPAR $y$ and cytoplasmic proteins, like (extracellular signal regulated kinase) ERK 1/2, and (mitogen-activated protein kinase) MAPK kinases, have been reported in cancer cells and functional importance has been given to the subcellular localization of PPAR $y$ [71, 72]. In this regard, in PC-3 prostate cancer cells, IGF-1R signaling has been shown to be attenuated by rosiglitazone via non-genomic action on ERK 1/2, and protein kinase AKT phosphorylation [73]. Therefore, both nuclear and cytoplasmic events may be theoretically operative in inhibiting the mitogenic signals common to the receptors of the IGF system (IR, IGF-1R and hybrid IR/IGF-1R).

The last three decades of medical research examining the molecular pathogenesis of cancers have provided compelling evidence for the universal disruption of the cell cycle in human tumours, and recent studies have demonstrated a critical interface between hormonal signaling and the cell cycle [74]. In this context, mitogens like insulin, via the IR, may promote the progression through the G1 phase by inducing competence of the cyclin D1/cyclin-dependent kinase 4 (CDK4) complex. It has been previously reported that the PPAR $\gamma$ agonists inhibit cyclin D1 [75]. Our findings on IR and PPAR $y$ support the conclusion that PPAR $y$ and TZDs may interfere with the hormonal control of the cell cycle, at least in part, through the inhibition of the IR. Over the last decade, PPAR $\gamma$ has emerged as an important drug target in type 2 diabetes mellitus [76], and TZDs are widely used for treatment of diabetic patients. However, conflicting results on the procarcinogenic and antitumorigenic effects of TZDs in humans with diabetes can be found in the literature. For instance, whereas a population based report showed that TZDs were associated with reduced risk of lung cancer in patients with diabetes [77], a possible association between cancer and the use of TZD has been reported later in type 2 diabetic patients [78]. Thus it is tempting to suppose that IR gene may be considered a new anticancer target for PPAR $\gamma$, providing further evidence for the use of TZDs as antiproliferative agents in selected tumours overexpressing the IR.

\section{Acknowledgments}

Research support has been received from Telethon-Italy (Grant GGP04245), and MIUR (Protocol 2004062059-002 Italy) to $\mathrm{AB}$.

\section{References}

[1] A. R. Saltiel and C. R. Kahn, "Insulin signalling and the regulation of glucose and lipid metabolism," Nature, vol. 414, no. 6865, pp. 799-806, 2001.

[2] I. D. Goldfine, "The insulin receptor: molecular biology and transmembrane signaling," Endocrine Reviews, vol. 8, no. 3, pp. 235-255, 1987.

[3] A. Ullrich, J. R. Bell, E. Y. Chen, et al., "Human insulin receptor and its relationship to the tyrosine kinase family of oncogenes," Nature, vol. 313, no. 6005, pp. 756-761, 1985. 
[4] M. F. White and C. R. Kahn, "The insulin signaling system," The Journal of Biological Chemistry, vol. 269, no. 1, pp. 1-4, 1994.

[5] O. M. Rosen, "Structure and function of insulin receptors," Diabetes, vol. 38, no. 12, pp. 1508-1511, 1989.

[6] E. Araki, F. Shimada, H. Uzawa, M. Mori, and Y. Ebina, "Characterization of the promoter region of the human insulin receptor gene: evidence for promoter activity," The Journal of Biological Chemistry, vol. 262, no. 33, pp. 1618616191, 1987.

[7] S. Seino, M. Seino, S. Nishi, and G. I. Bell, "Structure of the human insulin receptor gene and characterization of its promoter," Proceedings of the National Academy of Sciences of the United States of America, vol. 86, no. 1, pp. 114-118, 1989.

[8] A. Brunetti, D. P. Foti, and I. D. Goldfine, "Identification of unique nuclear regulatory proteins for the insulin receptor gene, which appear during myocyte and adipocyte differentiation," Journal of Clinical Investigation, vol. 92, no. 3, pp. 12881295, 1993.

[9] M. Jensen, B. Hansen, P. De Meyts, L. Schaeffer, and B. Urso, "Activation of the insulin receptor by insulin and a synthetic peptide leads to divergent metabolic and mitogenic signaling and responses," The Journal of Biological Chemistry, vol. 282, no. 48, pp. 35179-35186, 2007.

[10] P. De Meyts, "Insulin and its receptor: structure, function and evolution," BioEssays, vol. 26, no. 12, pp. 1351-1362, 2004.

[11] M. Malumbres and M. Barbacid, "To cycle or not to cycle: a critical decision in cancer," Nature Reviews Cancer, vol. 1, no. 3, pp. 222-231, 2001.

[12] C. M. Taniguchi, B. Emanuelli, and C. R. Kahn, "Critical nodes in signalling pathways: insights into insulin action," Nature Reviews Molecular Cell Biology, vol. 7, no. 2, pp. 85-96, 2006.

[13] A. A. Samani, S. Yakar, D. LeRoith, and P. Brodt, "The role of the IGF system in cancer growth and metastasis: overview and recent insights," Endocrine Reviews, vol. 28, no. 1, pp. 20-47, 2007.

[14] F. Frasca, G. Pandini, P. Scalia, et al., "Insulin receptor isoform A, a newly recognized, high-affinity insulin-like growth factor II receptor in fetal and cancer cells," Molecular and Cellular Biology, vol. 19, no. 5, pp. 3278-3288, 1999.

[15] A. Denley, J. C. Wallace, L. J. Cosgrove, and B. E. Forbes, “The insulin receptor isoform exon 11- (IR-A) in cancer and other diseases: a review," Hormone and Metabolic Research, vol. 35, no. 11-12, pp. 778-785, 2003.

[16] S. I. Taylor, "Deconstructing type 2 diabetes," Cell, vol. 97, no. 1, pp. 9-12, 1999.

[17] R. A. DeFronzo, D. Simonson, and E. Ferrannini, "Hepatic and peripheral insulin resistance: a common feature of type 2 (non-insulin-dependent) and type 1 (insulin-dependent) diabetes mellitus," Diabetologia, vol. 23, no. 4, pp. 313-319, 1982.

[18] C. B. Hollenbeck, Y. D. I. Chen, and G. M. Reaven, "A comparison of the relative effects of obesity and non-insulindependent diabetes mellitus on in vivo insulin-stimulated glucose utilization,” Diabetes, vol. 33, no. 7, pp. 622-626, 1984.

[19] S. B. Biddinger and C. R. Kahn, "From mice to men: insights into the insulin resistance syndromes," Annual Review of Physiology, vol. 68, pp. 123-158, 2006.

[20] S. I. Taylor, "Lilly lecture: molecular mechanisms of insulin resistance: lessons from patients with mutations in the insulinreceptor gene," Diabetes, vol. 41, no. 11, pp. 1473-1490, 1992.
[21] D. P. Foti, E. Chiefari, M. Fedele, et al., "Lack of the architectural factor HMGA1 causes insulin resistance and diabetes in humans and mice," Nature Medicine, vol. 11, no. 7, pp. 765-773, 2005.

[22] M. Pollak, "Insulin and insulin-like growth factor signalling in neoplasia," Nature Reviews Cancer, vol. 8, no. 12, pp. 915-928, 2008.

[23] F. Frasca, G. Pandini, L. Sciacca, et al., "The role of insulin receptors and IGF-I receptors in cancer and other diseases," Archives of Physiology and Biochemistry, vol. 114, no. 1, pp. 2337, 2008.

[24] V. Papa, V. Pezzino, A. Costantino, et al., "Elevated insulin receptor content in human breast cancer," Journal of Clinical Investigation, vol. 86, no. 5, pp. 1503-1510, 1990.

[25] J. H. Law, G. Habibi, K. Hu, et al., "Phosphorylated insulin-like growth factor-I/insulin receptor is present in all breast cancer subtypes and is related to poor survival," Cancer Research, vol. 68, no. 24, pp. 10238-10246, 2008.

[26] K. R. Kalli, O. I. Falowo, L. K. Bale, M. A. Zschunke, P. C. Roche, and C. A. Conover, "Functional insulin receptors on human epithelial ovarian carcinoma cells: implications for IGF-II mitogenic signaling," Endocrinology, vol. 143, no. 9, pp. 3259-3267, 2002.

[27] M. E. Cox, M. E. Gleave, M. Zakikhani, et al., "Insulin receptor expression by human prostate cancers," Prostate, vol. 69, no. 1, pp. 33-40, 2009.

[28] R. Schiel, W. Beltschikow, T. Steiner, and G. Stein, "Diabetes, insulin, and risk of cancer," Methods and Findings in Experimental and Clinical Pharmacology, vol. 28, no. 3, pp. 169-175, 2006.

[29] E. Giovannucci and D. Michaud, "The role of obesity and related metabolic disturbances in cancers of the colon, prostate, and pancreas," Gastroenterology, vol. 132, no. 6, pp. 2208-2225, 2007.

[30] C. K. Osborne, G. Bolan, M. E. Monaco, and M. E. Lippman, "Hormone responsive human breast cancer in long term tissue culture: effect of insulin," Proceedings of the National Academy of Sciences of the United States of America, vol. 73, no. 12, pp. 4536-4540, 1976.

[31] F. Paonessa, D. P. Foti, V. Costa, et al., "Activator protein2 overexpression accounts for increased insulin receptor expression in human breast cancer," Cancer Research, vol. 66, no. 10, pp. 5085-5093, 2006.

[32] S. Kolb, R. Fritsch, D. Saur, M. Reichert, R. M. Schmid, and G. Schneider, "HMGA1 controls transcription of insulin receptor to regulate cyclin D1 translation in pancreatic cancer cells," Cancer Research, vol. 67, no. 10, pp. 4679-4686, 2007.

[33] D. Sachdev and D. Yee, "Disrupting insulin-like growth factor signaling as a potential cancer therapy," Molecular Cancer Therapeutics, vol. 6, no. 1, pp. 1-12, 2007.

[34] P. W. Mamula, A. R. McDonald, A. Brunetti, et al., "Regulating insulin-receptor-gene expression by differentiation and hormones," Diabetes Care, vol. 13, no. 3, pp. 288-301, 1990.

[35] A. Brunetti, G. Manfioletti, E. Chiefari, I. D. Goldfine, and D. P. Foti, "Transcriptional regulation of human insulin receptor gene by the high-mobility group protein HMGI(Y)," The FASEB Journal, vol. 15, no. 2, pp. 492-500, 2001.

[36] D. P. Foti, R. Iuliano, E. Chiefari, and A. Brunetti, "A nucleoprotein complex containing Sp1, C/EBP $\beta$, and HMGIY controls human insulin receptor gene transcription," Molecular and Cellular Biology, vol. 23, no. 8, pp. 2720-2732, 2003. 
[37] B. Desvergne and W. Wahli, "Peroxisome proliferatoractivated receptors: nuclear control of metabolism," Endocrine Reviews, vol. 20, no. 5, pp. 649-688, 1999.

[38] J. Berger and D. E. Moller, "The mechanisms of action of PPARs," Annual Review of Medicine, vol. 53, pp. 409-435, 2002.

[39] S. A. Kliewer, H. E. Xu, M. H. Lambert, and T. M. Willson, "Peroxisome proliferator-activated receptors: from genes to physiology," Recent Progress in Hormone Research, vol. 56, pp. 239-263, 2001.

[40] E. D. Rosen, P. Sarraf, A. E. Troy, et al., "PPAR $\gamma$ is required for the differentiation of adipose tissue in vivo and in vitro," Molecular Cell, vol. 4, no. 4, pp. 611-617, 1999.

[41] H. Keller, C. Dreyer, J. Medin, A. Mahfoudi, K. Ozato, and W. Wahli, "Fatty acids and retinoids control lipid metabolism through activation of peroxisome proliferatoractivated receptor-retinoid X receptor heterodimers," Proceedings of the National Academy of Sciences of the United States of America, vol. 90, no. 6, pp. 2160-2164, 1993.

[42] H. Keller, A. Mahfoudi, C. Dreyer, et al., "Peroxisome proliferator-activated receptors and lipid metabolism," Annals of the New York Academy of Sciences, vol. 684, pp. 157-173, 1993.

[43] A. J. Vidal-Puig, R. V. Considine, M. Jimenez-Linan, et al., "Peroxisome proliferator-activated receptor gene expression in human tissues: effects of obesity, weight loss, and regulation by insulin and glucocorticoids," Journal of Clinical Investigation, vol. 99, no. 10, pp. 2416-2422, 1997.

[44] C. D. Allred and M. W. Kilgore, "Selective activation of PPAR $\gamma$ in breast, colon, and lung cancer cell lines," Molecular and Cellular Endocrinology, vol. 235, no. 1-2, pp. 21-29, 2005.

[45] N. P. Nunez, H. Liu, and G. G. Meadows, "PPAR- $\gamma$ ligands and amino acid deprivation promote apoptosis of melanoma, prostate, and breast cancer cells," Cancer Letters, vol. 236, no. 1, pp. 133-141, 2006.

[46] J. Padilla, K. Kaur, S. G. Harris, and R. P. Phipps, "PPAR- $\gamma$ mediated regulation of normal and malignant B lineage cells," Annals of the New York Academy of Sciences, vol. 905, pp. 97109, 2000.

[47] Y. Barak, M. C. Nelson, E. S. Ong, et al., "PPAR $\gamma$ is required for placental, cardiac, and adipose tissue development," Molecular Cell, vol. 4, no. 4, pp. 585-595, 1999.

[48] C. A. Maloney and W. D. Rees, "Gene-nutrient interactions during fetal development," Reproduction, vol. 130, no. 4, pp. 401-410, 2005.

[49] S. Kersten, B. Desvergne, and W. Wahli, "Roles of PPARS in health and disease," Nature, vol. 405, no. 6785, pp. 421-424, 2000 .

[50] N. S. Tan, L. Michalik, B. Desvergne, and W. Wahli, "Multiple expression control mechanisms of peroxisome proliferatoractivated receptors and their target genes," Journal of Steroid Biochemistry and Molecular Biology, vol. 93, no. 2-5, pp. 99105, 2005.

[51] F.-S. Chou, P.-S. Wang, S. Kulp, and J. J. Pinzone, "Effects of thiazolidinediones on differentiation, proliferation, and apoptosis," Molecular Cancer Research, vol. 5, no. 6, pp. 523530, 2007.

[52] J. M. Lehmann, L. B. Moore, T. A. Smith-Oliver, W. O. Wilkison, T. M. Willson, and S. A. Kliewer, "An antidiabetic thiazolidinedione is a high affinity ligand for peroxisome proliferator-activated receptor $\gamma(\operatorname{PPAR} \gamma)$," The Journal of Biological Chemistry, vol. 270, no. 22, pp. 12953-12956, 1995.
[53] A. R. Saltiel and J. M. Olefsky, "Thiazolidinediones in the treatment of insulin resistance and type II diabetes," Diabetes, vol. 45, no. 12, pp. 1661-1669, 1996.

[54] C. Jiang, A. T. Ting, and B. Seed, "PPAR- $\gamma$ agonists inhibit production of monocyte inflammatory cytokines," Nature, vol. 391, no. 6662, pp. 82-86, 1998.

[55] M. Li, G. Pascual, and C. K. Glass, "Peroxisome proliferatoractivated receptor $\gamma$-dependent repression of the inducible nitric oxide synthase gene," Molecular and Cellular Biology, vol. 20, no. 13, pp. 4699-4707, 2000.

[56] M. Ricote, A. C. Li, T. M. Willson, C. J. Kelly, and C. K. Glass, "The peroxisome proliferator-activated receptor- $\gamma$ is a negative regulator of macrophage activation," Nature, vol. 391, no. 6662, pp. 79-82, 1998.

[57] C. Yu, K. Markan, K. A. Temple, D. Deplewski, M. J. Brady, and R. N. Cohen, "The nuclear receptor corepressors NCoR and SMRT decrease peroxisome proliferator-activated receptor $\gamma$ transcriptional activity and repress 3T3-L1 adipogenesis," The Journal of Biological Chemistry, vol. 280, no. 14, pp. 1360013605, 2005.

[58] P. Tontonoz, E. Hu, and B. M. Spiegelman, "Stimulation of adipogenesis in fibroblasts by PPAR $\gamma 2$, a lipid-activated transcription factor," Cell, vol. 79, no. 7, pp. 1147-1156, 1994.

[59] E. Mueller, P. Sarraf, P. Tontonoz, et al., "Terminal differentiation of human breast cancer through PPAR $\gamma$," Molecular Cell, vol. 1, no. 3, pp. 465-470, 1998.

[60] V. Costa, D. P. Foti, F. Paonessa, et al., "The insulin receptor: a new anticancer target for peroxisome proliferator-activated receptor- $\gamma(\operatorname{PPAR} \gamma)$ and thiazolidinedione- PPAR $\gamma$ agonists," Endocrine-Related Cancer, vol. 15, no. 1, pp. 325-335, 2008.

[61] C. K. Osborne, M. E. Monaco, M. E. Lippman, and C. R. Kahn, "Correlation among insulin binding, degradation, and biological activity in human breast cancer cells in long term tissue culture," Cancer Research, vol. 38, no. 1, pp. 94-102, 1978.

[62] G. Milazzo, F. Giorgino, G. Damante, et al., "Insulin receptor expression and function in human breast cancer cell lines," Cancer Research, vol. 52, no. 14, pp. 3924-3930, 1992.

[63] N. R. Farid, Y. Shi, and M. Zou, "Molecular basis of thyroid cancer," Endocrine Reviews, vol. 15, no. 2, pp. 202-232, 1994.

[64] C. Grommes, G. E. Landreth, and M. T. Heneka, "Antineoplastic effects of peroxisome proliferator-activated receptor $\gamma$ agonists," The Lancet Oncology, vol. 5, no. 7, pp. 419-429, 2004.

[65] A. Sugawara, A. Uruno, M. Kudo, et al., "Transcription suppression of thromboxane receptor gene by peroxisome proliferator-activated receptor- $\gamma$ via an interaction with Sp1 in vascular smooth muscle cells," The Journal of Biological Chemistry, vol. 277, no. 12, pp. 9676-9683, 2002.

[66] J. Hong, I. Samudio, S. Liu, M. Abdelrahim, and S. Safe, "Peroxisome proliferator-activated receptor $\gamma$-dependent activation of $\mathrm{p} 21$ in Panc-28 pancreatic cancer cells involves Sp1 and Sp4 proteins," Endocrinology, vol. 145, no. 12, pp. 57745785, 2004.

[67] S. Han, J. D. Ritzenthaler, H. N. Rivera, and J. Roman, "Peroxisome proliferator-activated receptor- $\gamma$ ligands suppress fibronectin gene expression in human lung carcinoma cells: involvement of both CRE and Sp1," American Journal of Physiology, vol. 289, no. 3, pp. L419-L428, 2005.

[68] E. Elstner, C. Muller, K. Koshizuka, et al., "Ligands for peroxisome proliferator-activated receptor $\gamma$ and retinoic acid receptor inhibit growth and induce apoptosis of human breast 
cancer cells in vitro and in BNX mice," Proceedings of the National Academy of Sciences of the United States of America, vol. 95, no. 15, pp. 8806-8811, 1998.

[69] D. J. Mulholland, S. Dedhar, G. A. Coetzee, and C. C. Nelson, "Interaction of nuclear receptors with the $\mathrm{Wnt} / \beta$-catenin/Tcf signaling axis: Wnt you like to know?" Endocrine Reviews, vol. 26, no. 7, pp. 898-915, 2005.

[70] L. Patel, I. Pass, P. Coxon, C. P. Downes, S. A. Smith, and C. H. Macphee, "Tumor suppressor and anti-inflammatory actions of PPAR $\gamma$ agonists are mediated via upregulation of PTEN," Current Biology, vol. 11, no. 10, pp. 764-768, 2001.

[71] E. Burgermeister and R. Seger, "MAPK kinases as nucleocytoplasmic shuttles for PPAR $\gamma$," Cell Cycle, vol. 6, no. 13, pp. 1539-1548, 2007.

[72] E. Papageorgiou, N. Pitulis, P. Msaouel, P. Lembessis, and M. Koutsilieris, "The non-genomic crosstalk between PPAR$\gamma$ ligands and ERK1/2 in cancer cell lines," Expert Opinion on Therapeutic Targets, vol. 11, no. 8, pp. 1071-1085, 2007.

[73] E. Papageorgiou, N. Pitulis, M. Manoussakis, P. Lembessis, and M. Koutsilieris, "Rosiglitazone attenuates insulin-like growth factor 1 receptor survival signaling in PC-3 cells," Molecular Medicine, vol. 14, no. 7-8, pp. 403-411, 2008.

[74] L. Hilakivi-Clarke, C. Wang, M. Kalil, R. Riggins, and R. G. Pestell, "Nutritional modulation of the cell cycle and breast cancer," Endocrine-Related Cancer, vol. 11, no. 4, pp. 603-622, 2004.

[75] C. Wang, M. Fu, M. D’Amico, et al., "Inhibition of cellular proliferation through $\mathrm{I} \kappa \mathrm{B}$ kinase-independent and peroxisome proliferator-activated receptor $\gamma$-dependent repression of cyclin D1," Molecular and Cellular Biology, vol. 21, no. 9, pp. 3057-3070, 2001.

[76] R. S. Savkur and A. R. Miller, "Investigational PPAR- $\gamma$ agonists for the treatment of type 2 diabetes," Expert Opinion on Investigational Drugs, vol. 15, no. 7, pp. 763-778, 2006.

[77] R. Govindarajan, L. Ratnasinghe, D. L. Simmons, et al., "Thiazolidinediones and the risk of lung, prostate, and colon cancer in patients with diabetes," Journal of Clinical Oncology, vol. 25, no. 12, pp. 1476-1481, 2007.

[78] M. E. Ramos-Nino, C. D. MacLean, and B. Littenberg, "Association between cancer prevalence and use of thiazolidinediones: results from the Vermont Diabetes Information System," BMC Medicine, vol. 5, article 17, pp. 1-7, 2007. 


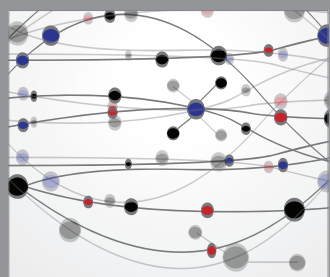

The Scientific World Journal
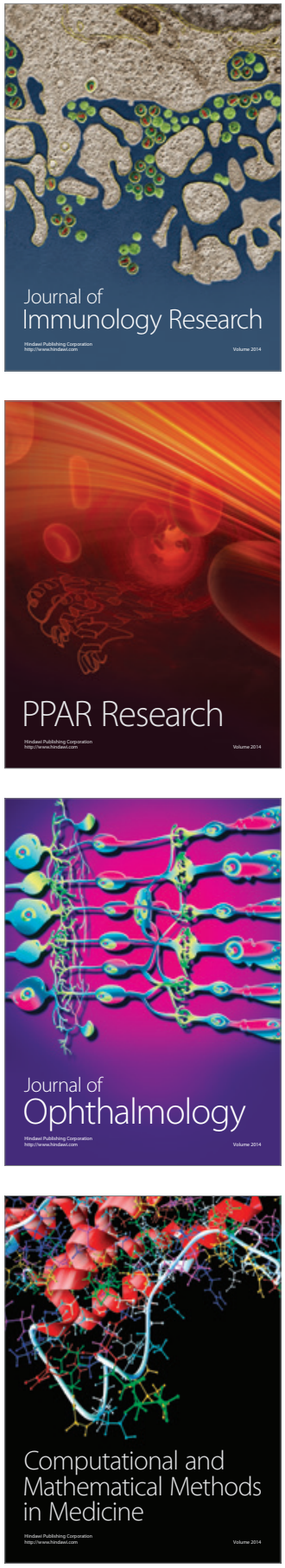

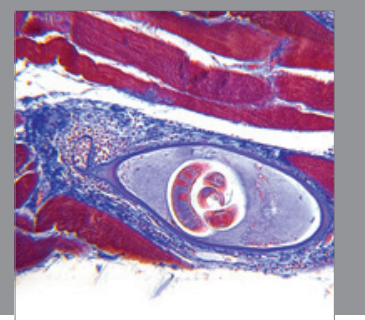

Gastroenterology

Research and Practice
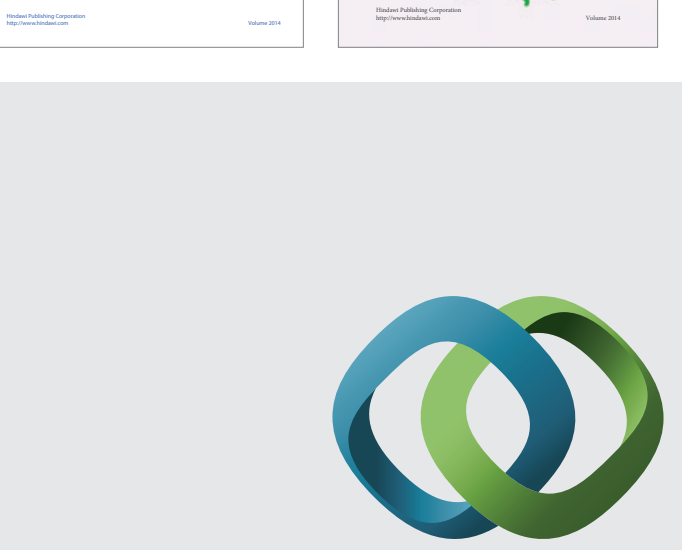

\section{Hindawi}

Submit your manuscripts at

http://www.hindawi.com
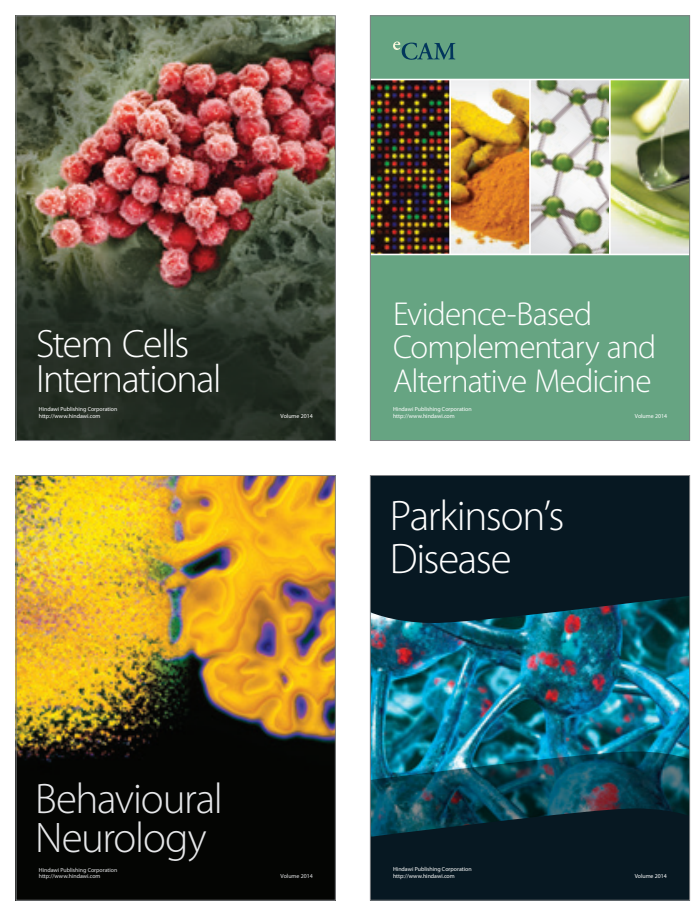

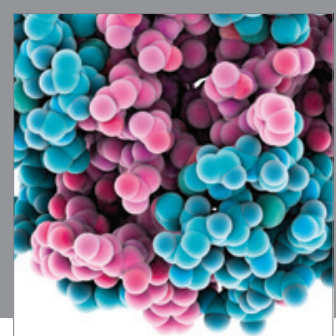

Journal of
Diabetes Research

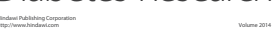

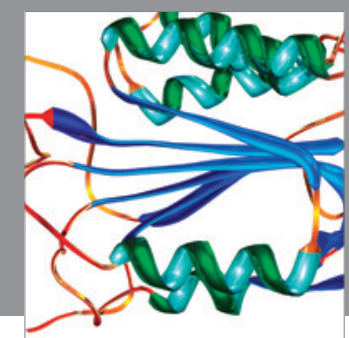

Disease Markers
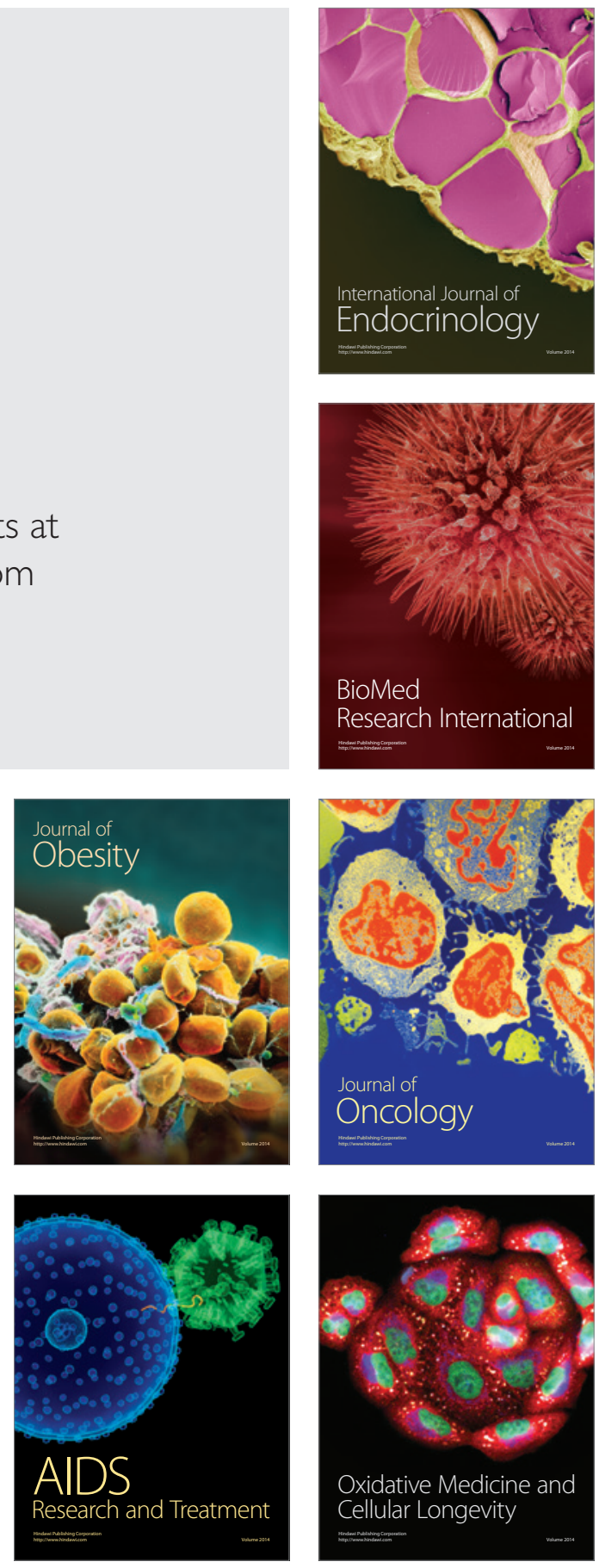